\author{
Włodzimierz Czyczuła \\ Prof. dr hab. inż. \\ Politechnika Krakowska \\ czyczula@pk.edu.pl \\ Lukasz Chudyba \\ Dr inż. \\ Politechnika Krakowska \\ lchudyba@poczta.onet.pl
}

DOI: 10.35117/A_ENG_18_07_01

\title{
Dynamic response of rail track in longitudinal direction
}

\begin{abstract}
The paper presents an analysis of linear models track response under longitudinal loads due to braking/accelerating of the train. Longitudinal forces are uniformly distributed on the whole length of the train. Analysis was carried out under assumption that - in the short time - train speed not changes significantly. Therefore stationary response of rail track is considered. The problem of critical speed has been analyzed. Effect of damping properties of track foundation on maximum longitudinal displacements were also considered. In summary certain practical conclusions were formulated as well as the further investigations were pointed out.
\end{abstract}

Keywords: Rail track; Braking/Accelerating of train; Analytical track models; Rail longitudinal displacements

\section{Introduction}

Analysis of the dynamic response of a railroad is mainly related to the vertical plane (see e.g. $[1,2,4,9])$. The analysis in the horizontal plane (in the transverse and longitudinal direction) concerns relatively few works, both theoretical and experimental (see e.g. [5-7,10-11,13-14]). Work on longitudinal interactions, or more precisely braking and speeding up of a train, mainly concerns the dynamics of vehicles and simulated theoretical trains (see e.g. [12]).

In the work the model of the rail way in the longitudinal direction is considered at loads resulting from braking / accelerating the train. It is assumed that in a small time interval during braking / accelerating the train speed does not change significantly - that is why the stationary response of a railroad is considered, both in the case of acceleration and braking of the train. Longitudinal forces are determined by multiplying vertical forces by the assumed coefficient, also called the braking / acceleration intensity coefficient.

\section{Rail track and load model}

The rail track is modeled as a substitute beam, resting on a resilient-sticky substrate. The beam consists of two rails, described by two parameters: longitudinal stiffness $E A$ (where $E-$ Young's modulus of the rail steel $\left[\mathrm{N} / \mathrm{m}^{2}\right], A$ - cross-sectional area of two rails $\left.\left[\mathrm{m}^{2}\right]\right)$ and unit weight $m[\mathrm{~kg} / \mathrm{m}]$, which concerns both the unit weight of the two rails as well as, if applicable, the weight of the sleepers and fittings per unit length of the track.

The rail substrate is described by two parameters: unit stiffness $k\left[\mathrm{~N} / \mathrm{m}^{2}\right]$ and a unit damping factor $c\left[\mathrm{Ns} / \mathrm{m}^{2}\right]$. These parameters characterize the longitudinal properties of fastening rails to sleepers and longitudinal resistance when the sleepers under ballast move. Two hypotheses of the impact of load on the longitudinal stiffness of the rail substrate are considered: stiffness does not depend on the vertical load, but stiffness increases as the 
vertical load increases. Both hypotheses are confirmed in experimental studies, although most studies show that this effect is negligible and the assumption of stiffness not dependent on vertical load is justified [5]. Nevertheless, in the course of further deliberations, we will analyze both cases. With regard to the other parameters of the rail track, we assume that they are fixed along the track.

As already mentioned, the longitudinal loading will be considered as train acceleration and braking forces in a small time interval in which the train speed does not change significantly. The following load model will be considered in the work:

1. The longitudinal forces at the interface between the wheels and the rails are evenly distributed over the entire length of the train. This assumption, in a static solution, was verified in paper [5]. It has been shown that even load in relation to - statically equivalent - discrete load does not introduce significant errors. This applies in particular to the zone of maximum values of longitudinal displacements.

2. Longitudinal loading $\theta[\mathrm{N} / \mathrm{m}]$ depends on the vertical load $q[\mathrm{~N} / \mathrm{m}]$, and this relationship is described by the formula:

$$
\theta=\mu \cdot q
$$

where $\mu$-dimensionless coefficient (smaller than the sliding friction coefficient)).

Rail track without damping and with track rigidity independent of vertical load $\left(k(x)=k_{0}=\right.$ const. $)$

Equation of track motion without damping, with constant rigidity of the rail foundation $k_{o}$ and load $\theta$, evenly distributed over the entire length of the train $2 l_{t}$, has form (compar. [5]):

$E A \frac{\partial^{2} u}{\partial x^{2}}-m \frac{\partial^{2} u}{\partial t^{2}}-k_{o} u=-\theta(x, t) ; \quad$ under the train

$E A \frac{\partial^{2} u}{\partial x^{2}}-m \frac{\partial^{2} u}{\partial t^{2}}-k_{o} u=0 ; \quad$ outside the train

where:

$u(x, t)$ - longitudinal displacement of the substitute beam (rails), other markings - as in the previous chapter.

In a mobile coordinate system $(\eta=u, \xi=x-v t)$, whose center is at the middle point of the train, where $v$-train speed, if the load does not change over time, equation (2) can be saved in the form of ordinary equations:

$\frac{d^{2} u}{d \xi^{2}}-\beta^{2} u=-\frac{\theta}{E A-m v^{2}} ; d l a|\xi| \leq l_{t}$

$\left.\frac{d^{2} u}{d \xi^{2}}-\beta^{2} u=0 ; d l a|\xi|\right\rangle l_{t}$

where:

$\beta=\sqrt{\frac{k_{o}}{E A-m v^{2}}}$ 
It is easy to see that equations (3) make sense when the speed of the train $v$ is less than the critical value $v_{c r}$, that is:

$v\left\langle v_{c r}=\sqrt{\frac{E A}{m}}\right.$

The general solution of the equation (3.2a), taking into account the special integral, can be written in the form:

$u(\xi)=C_{1} \cdot \operatorname{ch}(\beta \xi)+C_{2} \cdot \operatorname{sh}(\beta \xi)+\frac{\theta}{k_{o}} ;$ dla $|\xi| \leq l_{t}$

while the general integral of the equation (3.2b) will take the form:

$\left.u(\xi)=D_{1} \cdot e^{-\beta\left(\xi-l_{t}\right)}+D_{2} \cdot e^{\beta\left(\xi-l_{t}\right)} ; d l a|\xi|\right\rangle l_{t}$

where: $C_{1}, C_{2}, D_{1}, D_{2}-$ constant.

Symmetrical solution to the point $\xi=0$, considering positive values $\xi$, can be obtained by adopting the following boundary conditions and conditions for the continuity of functions and its derivatives at the end of the train:

$g d y \xi \rightarrow 0^{+} ; \frac{d u}{d \xi} \rightarrow 0 ;$

$g d y \xi \rightarrow \infty ; u \rightarrow 0$

$u\left(\xi=l_{t}^{+}\right)=u\left(\xi=l_{t}^{-}\right)$;

$\frac{d u}{d \xi}\left(\xi=l_{t}^{+}\right)=\frac{d u}{d \xi}\left(\xi=l_{t}^{-}\right)$

For these boundary conditions a stationary solution to the problem, for positive values $\xi$, will take the form:

$$
\begin{aligned}
& u(\xi)=\frac{\theta}{k_{o}} \cdot\left(1-\frac{\operatorname{ch}(\beta \xi)}{\operatorname{ch}\left(\beta l_{t}\right)+\operatorname{sh}\left(\beta l_{t}\right)}\right) ; g d y \xi \leq l_{t} \\
& \left.u(\xi)=\frac{\theta}{k_{o}} \cdot\left(\frac{\operatorname{sh}\left(\beta l_{t}\right)}{\operatorname{ch}\left(\beta l_{t}\right)+\operatorname{sh}\left(\beta l_{t}\right)}\right) \cdot e^{-\beta\left(\xi-l_{t}\right)} ; g d y \xi\right\rangle l_{t}
\end{aligned}
$$

and the solution is symmetrical with respect to the point $\xi=0$.

\section{The solution without damping, depending on the vertical load}

We assume that the longitudinal stiffness of the railroad under the train, along its entire length, is in the form:

$k_{p}=k_{o}+\frac{q_{p} \cdot \varphi}{u_{\lim }}\left[\mathrm{N} / \mathrm{m}^{2}\right]$

where: $k_{o}$ - longitudinal stiffness of unloaded track $\left[\mathrm{N} / \mathrm{m}^{2}\right]$ (compare equations $\left.(2)\right), q_{p}-$ the unit vertical load of the train falling on the sleepers $[\mathrm{N} / \mathrm{m}], \varphi[-], u_{\text {lim }}[\mathrm{m}]-$ coefficient of friction of the foundation against ballast at longitudinal loads and limit value of elastic displacement of the foundation in the ballast in the longitudinal direction.

All these values must be determined experimentally, under laboratory conditions (see e.g. [5]). With this assumption the equation (2) will take the form: 
$E A \frac{\partial^{2} u}{\partial x^{2}}-m \frac{\partial^{2} u}{\partial t^{2}}-k_{p} u=-\theta(x, t) ;$ under the train

$E A \frac{\partial^{2} u}{\partial x^{2}}-m \frac{\partial^{2} u}{\partial t^{2}}-k_{o} u=0 ; \quad$ outside the train

In a mobile coordinate system $(\eta=u, \xi=x-v t)$, where $v$ - train speed, if the load does not change over time, equation (10) can be saved in the form of ordinary equations:

$\frac{d^{2} u}{d \xi^{2}}-\beta_{p}^{2} u=-\frac{\theta}{E A-m v^{2}} ; d l a|\xi| \leq l_{t}$

$\left.\frac{d^{2} u}{d \xi^{2}}-\beta^{2} u=0 ; d l a|\xi|\right\rangle l_{t}$

where:

$\beta_{p}=\sqrt{\frac{k_{p}}{E A-m v^{2}}}$

$\beta$ - as in the formula (4).

As can be seen, also in the case of a variable rail vehicle stiffness, the critical speed has the same value as in the case of constant stiffness (see formula (5) and (12)).

Using the same reasoning method and the same boundary conditions as in the case of constant longitudinal stiffness, solving the problem, i.e. stationary track response with longitudinal load uniformly distributed along the train, for positive values of the argument $\xi$, will have form:

$$
\begin{aligned}
& u(\xi)=\frac{\theta}{k_{p}} \cdot\left(1-\frac{\operatorname{ch}\left(\beta_{p} \xi\right)}{\operatorname{ch}\left(\beta_{p} l_{t}\right)+\omega \cdot \operatorname{sh}\left(\beta_{p} l_{t}\right)}\right) ; g d y \xi \leq l_{t} \\
& \left.u(\xi)=\frac{\theta}{k_{p}} \cdot\left(\frac{\omega \cdot \operatorname{sh}\left(\beta_{p} l_{t}\right)}{\operatorname{ch}\left(\beta_{p} l_{t}\right)+\omega \cdot \operatorname{sh}\left(\beta_{p} l_{t}\right)}\right) \cdot e^{-\beta\left(\xi-l_{t}\right)} ; g d y \xi\right\rangle l_{t}
\end{aligned}
$$

where $\omega=\beta_{p} / \beta$.

and the solution is symmetric with respect to the point $\xi=0$.

As you can see, the structure of formulas (13), due to the functions that occur, is identical to the formulas (8).

Summarizing the considerations regarding the track response under homogeneous unit load in the absence of attenuation, the following observations can be made:

1. The critical speed for a loaded track in the longitudinal direction does not depend on the stiffness of the rail base. This applies to both the constant stiffness hypothesis, independent of the vertical load, and the case in which the vertical load increases the longitudinal stiffness of the rail substrate. For typical parameters of pavement construction, the critical speed is at the level of $4000-7000 \mathrm{~km} / \mathrm{h}$ (formula (5)). This means that the critical speed of the surface in the longitudinal direction is significantly higher than in the case of vertical and transverse loads to the track axis (the critical speed at 1000-1500 km/h, compare e.g. $[1,4,8]$ ). The calculations show that for typical track parameters, at speeds up to around $500 \mathrm{~km} / \mathrm{h}$, the dynamic coefficient associated with the increase in longitudinal displacements can be neglected and treated as a static 
load. This applies to the load evenly distributed along the train and unchanged during the movement of the train.

2. Stationary path response, described by equations (8) and (13) should be treated as a strict solution to the problem. This solution, in the case of static load, has been verified numerically [5]. Taking into account the observations formulated above, it can be concluded that this solution describes well the cases currently occurring in the railways (speeds below $300-350 \mathrm{~km} / \mathrm{h}$ ). On the basis of numerical analyzes, a good agreement between the solution and statically equivalent load from the concentrated forces system [5] was also demonstrated, especially in the area of maximum longitudinal displacement of the track.

\section{Surface with damping under constant load}

The equation of motion in the general case, when we consider the damping of the rail substrate $c\left[\mathrm{Ns} / \mathrm{m}^{2}\right]$, and the unit load is described by any function $\theta(x, t)$, has a form:

$-E A \frac{\partial^{2} u}{\partial x^{2}}+m \frac{\partial^{2} u}{\partial t^{2}}+c \frac{\partial u}{\partial t}+k_{o} u=\theta(x, t)$

It has been assumed that the longitudinal stiffness of the rail substrate does not depend on the load, therefore, over the entire length of the analyzed track section it is constant and amounts to $k_{o}$. In the mobile coordinate system, $(\eta=u, \xi=x-v t)$, in case of a constant, unchanging load, the equation (14) can be written in the form of the following ordinary equation:

$\left(m v^{2}-E A\right) \frac{d^{2} u}{d \xi^{2}}-c v \frac{d u}{d \xi}+k_{o} u=\theta(\xi)$

The calculations showed that the solution (13), for typical pavement and load structures, is practically zero for points distant from the ends of the train by more than 200$250 \mathrm{~m}$. Therefore, we will assume that both the solution of equation (15), i.e. the longitudinal displacement function, as well as the load can be written in the form of an infinite Fourier series, but in a finite range $[0, \lambda]$ :

$\theta(\xi)=\frac{a_{0}}{2}+\sum_{i=1}^{\infty}\left(a_{i} \cdot \cos \Omega_{i} \xi+b_{i} \cdot \sin \Omega_{i} \xi\right) ;$

$u(\xi)=\frac{u_{0}}{2}+\sum_{i=1}^{\infty}\left(A_{i} \cdot \cos \Omega_{i} \xi+B_{i} \cdot \sin \Omega_{i} \xi\right) ;$

$\xi \in[0, \lambda] ; \Omega_{i}=\frac{2 \pi \cdot i}{\lambda}$

After differentiating the function (16), substituting the received expressions to equation (15) and after ordering, we get the following set of algebraic equations to unknown values $A_{i}, B_{i}$ and $u_{o}$ :

$\left[-\left(m v^{2}-E A\right) \cdot \Omega_{i}^{2}+k\right] A_{i}+\left[-c v \Omega_{i}\right] B_{i}=a_{i}$

$\left[c \nu \Omega_{i}\right] A_{i}+\left[-\left(m v^{2}-E A\right) \cdot \Omega_{i}^{2}+k\right] B_{i}=b_{i}$

$u_{0}=\frac{a_{0}}{k}$

The number $a_{o}$, as well as coefficients $a_{i}$ and $b_{i}$ - for a rectangular distribution of the longitudinal load along the whole train - one can determine from analytical formulas with arbitrarily high accuracy and for a finite number of Fourier coefficients. Preliminary 
calculations showed that under the assumption of 1000 Fourier coefficients $(i=1,, n, n=$ 1000 ), with the assumption $\lambda=$ train length $+2 * 250 \mathrm{~m}$, solution (13) is identical to the solution (15), using the formulas (16) and equations (17) for the ground damping coefficient $c=0$.

\section{Examples of calculations}

The calculations were carried out for the following rail and load parameters (based on [3.5] and other own works of the Cracow University of Technology):

1. Rail track: tracks $60 \mathrm{E} 1, E=2,1 * 10^{11} \mathrm{~N} / \mathrm{m}^{2}, A=2 * 7687 * 10^{-6} \mathrm{~m}^{2}, m=2 * 60 \mathrm{~kg} / \mathrm{m}$ (tracks) $+320 \mathrm{~kg} / 0,6 m$ (PS-94 type sleepers) $=653,3 \mathrm{~kg} / \mathrm{m}$ (also only tracks, $m=120$ $\mathrm{kg} / \mathrm{m}$ ), longitudinal stiffness of the rail substrate $k=2500-7520 \mathrm{kN} / \mathrm{m}^{2}$, separate damping coefficient of the substrate $c=3511 \mathrm{Ns} / \mathrm{m}^{2}$ (basic value), also up to $1755500 \mathrm{Ns} / \mathrm{m}^{2}$ (500 times the basic value);

2. Load: train EMU-250 (Pendolino), about the distance between the extreme axes $2 l_{t}=$ $185 \mathrm{~m}, 28$ axes $* 160 \mathrm{kN} /$ axis, unit vertical load $q=24,22 \mathrm{kN} / \mathrm{m}$, unitary constant longitudinal loading $\theta=\mu q, \mu=0,2 ; \theta=4,84 \mathrm{kN} / \mathrm{m}$;

3. Other parameters: train speed $v-$ up to $850 \mathrm{~km} / \mathrm{h}$; the number of Fourier coefficients $n$ - to 1000 .

Figure 1 shows the functions of longitudinal displacement of the track during braking of the Pendolino train in the case of the constant stiffness hypothesis of the ground $\left(k_{o}=4500\right.$ $\mathrm{kN} / \mathrm{m}^{2}$ ) and variable stiffness - outside the train $4500 \mathrm{kN} / \mathrm{m}^{2}$, and under the train $k_{p}=7520$ $\mathrm{kN} / \mathrm{m}^{2}$ (this value was adopted on the basis of the few experimental studies that confirm this hypothesis - on the basis of [5]).

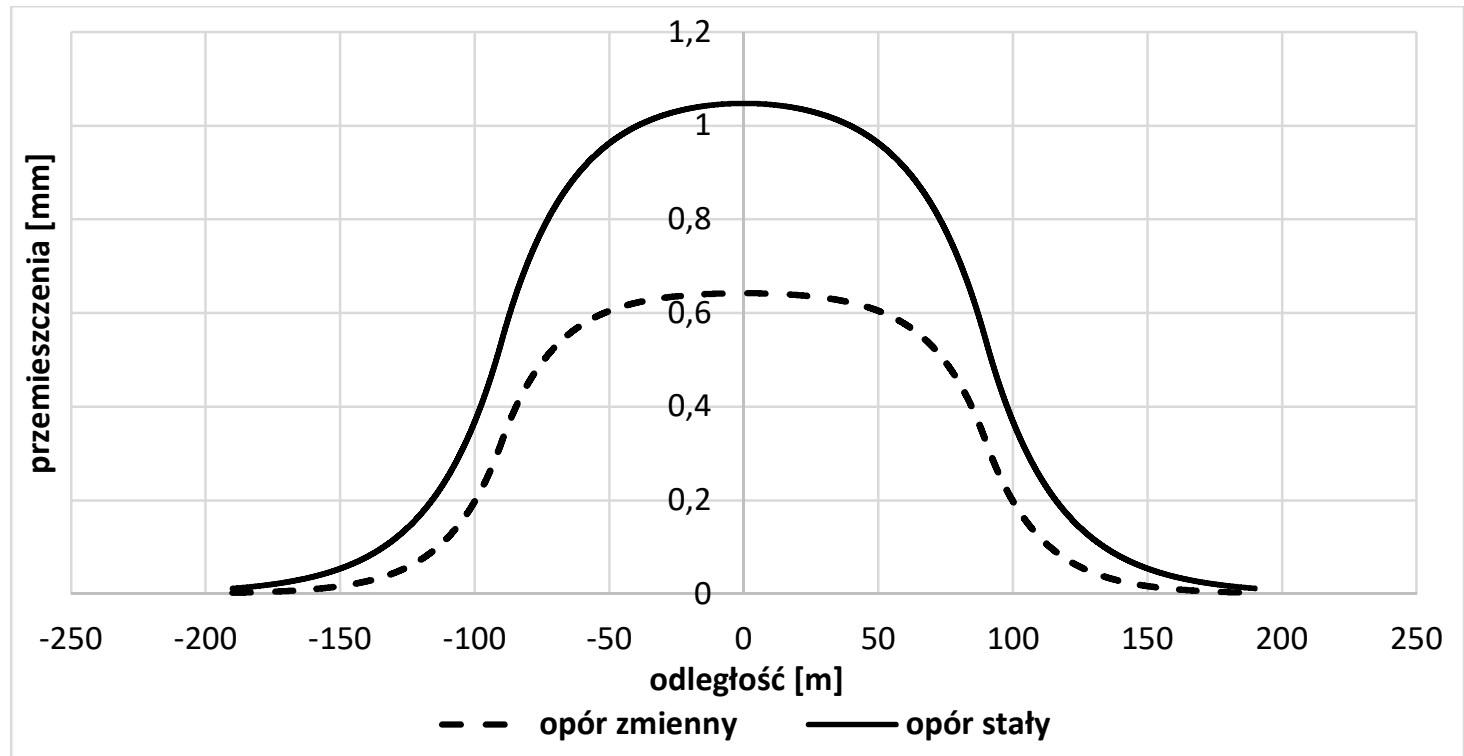

1. The distribution of longitudinal displacements when braking the EMU-250 train (Pendolino) with the adoption of two hypotheses of the effect of vertical load on longitudinal rigidity of the rail substrate

In the case of variable soil stiffness, longitudinal displacements are significantly smaller - in the analyzed example by about $40 \%$. From the engineering point of view, the hypothesis of constant stiffness, as giving higher values of displacements, is more useful therefore further calculations will be carried out assuming $k=k_{o}=$ const.

Figure 2 shows the effect of substrate stiffness on the maximum longitudinal displacement. The values $\mathrm{k}=4500 \mathrm{kN} / \mathrm{m}^{2}$ corresponds to a well-maintained track, values $7500 \mathrm{kN} / \mathrm{m}^{2}$ - very well maintained track, while values $3500 \mathrm{kN} / \mathrm{m}^{2}$ and below, medium and poorly maintained 
track. As can be seen, the influence of longitudinal stiffness on the maximum displacement is significant. From the formulas (8) and (13) it can be seen that the intensity of the load $\theta$ it is directly proportional to displacements - therefore, showing this relationship graphically does not make sense.

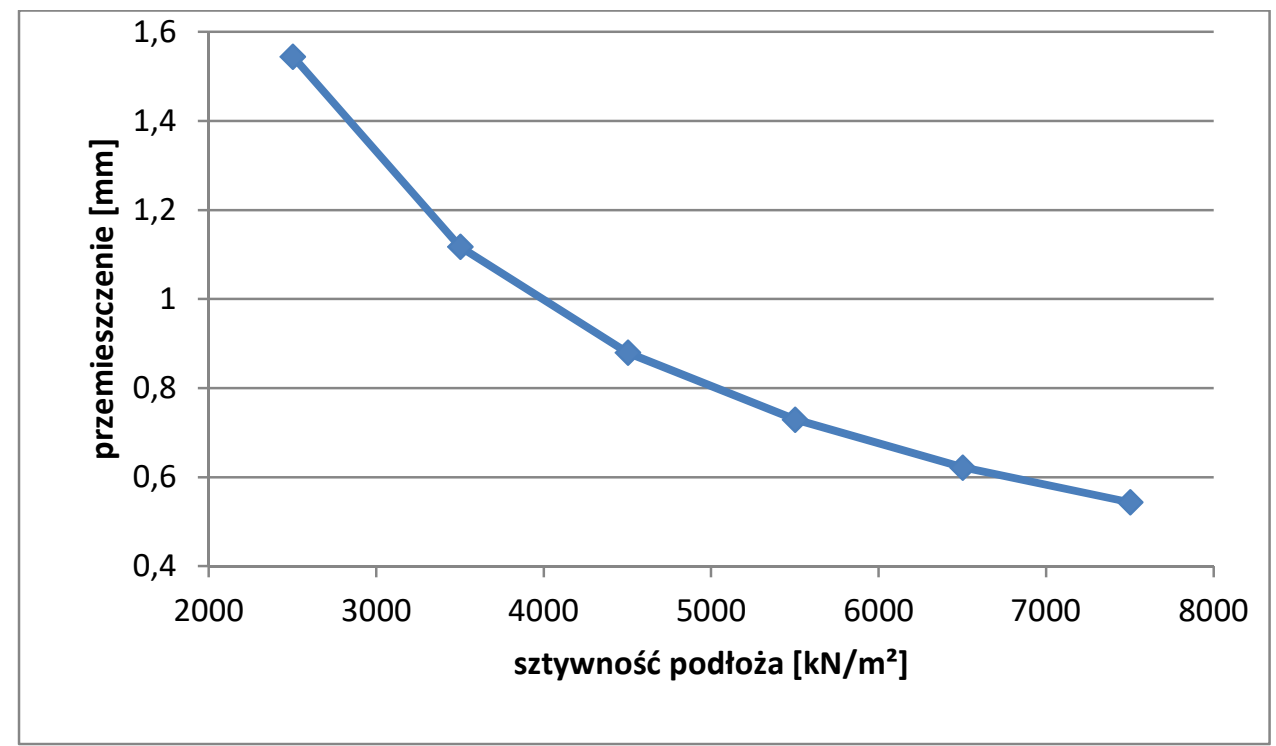

2. Influence of longitudinal stiffness of the rail substrate on the maximum displacement under the EMU-250 train (Pendolino) at the speed $250 \mathrm{~km} / \mathrm{h}$

As already indicated, the critical speed in the case of longitudinal loads, determined in the absence of damping of the rail substrate is very high and significantly exceeds the current operating speeds. By introducing the basic value of attenuation based on tests, that is $c=3511$ $\mathrm{Ns} / \mathrm{m}^{2}$, a constant value of maximum displacements is obtained up to over $500 \mathrm{~km} / \mathrm{h}$ changes smaller than fractions of one promil. Only a 500-fold increase in the damping coefficient causes the maximum deflection to decrease; at a speed of $350 \mathrm{~km} / \mathrm{h}$, the drop is just 3\%. This effect is illustrated in Figure 3.

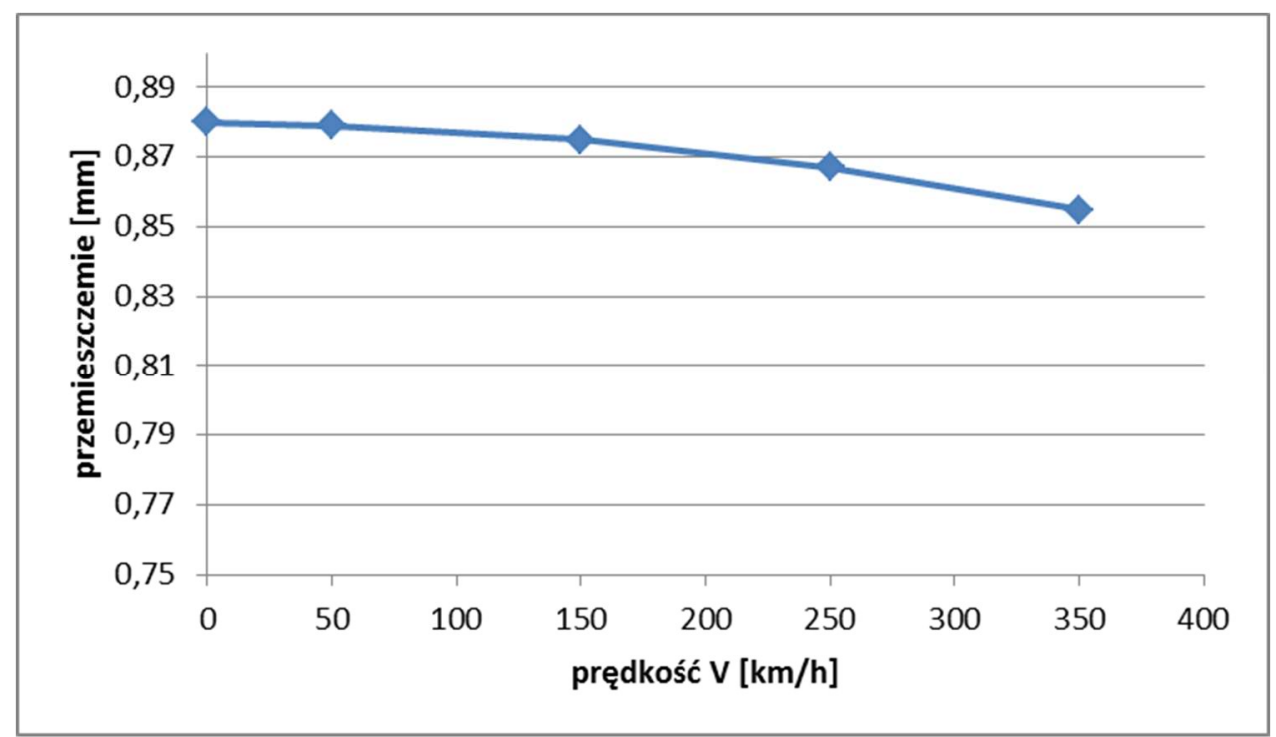

3. The effect of train speed on the maximum longitudinal displacement (damping factor 500 times higher than the basic one) 


\section{Summary and Conclusions}

The paper presents the issue of the railways response with longitudinal loads. Three linear analytical models were analyzed: two concerning the track without ground suppression, with two hypotheses of the effect of vertical load on longitudinal rigidity and one for the rail track with damping. The longitudinal loading was assumed to be constant, immutable over time and evenly distributed over the entire length of the train. The following conclusions come from the analysis:

1. The critical speed at longitudinal loads, regardless of the hypothetical effect of vertical load on the longitudinal stiffness of the rail substrate, is many times higher than the critical speed in the case of vertical and transverse loads. The critical speed depends only on the longitudinal stiffness of the rails and the mass involved in the longitudinal vibration of the track.

2. The consequence of this is the fact that - along with the increase in speed - the shape of the displacement function changes to a very small degree, and their maximum value is constant to speeds above $500 \mathrm{~km} / \mathrm{h}$ with accuracy to fractions of a promil.

3. The introduction of damping with the value of the coefficient resulting from experimental tests does not change the impact of velocity on the maximum deflections. Only with very high damping (damping factor up to 500 times higher than the basic one, resulting from experimental tests) there are slight changes - at the speed of $350 \mathrm{~km} / \mathrm{h}$, the change compared to the speed close to zero is just $3 \%$.

4. In engineering applications, when analyzing the path responses to permanent (immutable in time) loads resulting from braking and accelerating the train, a static model can be used, in which three parameters are important: intensity of longitudinal load, longitudinal stiffness of the substrate and longitudinal stiffness of rails.

5. Further work of the authors in this area will be focused on studies of the effect of variable loads over time, analysis of variable load distribution along the train and change of speed during acceleration and braking of the train, i.e. analysis of nonstationary states.

\section{Source materials}

[1] Bogacz R., Czyczuła W. Response of beam on visco-elastic foundation to moving distributed load. Journal of Theoretical and Applied Mechanics, 2008, 46, 4, pp. 63-775

[2] Bryja D., Popiołek A. - Analiza drgań pojazdów kolejowych w trakcie ich przejazdu przez nierówność progową toru. Przegląd Komunikacyjny, 2015, nr 9, s. 68-72

[3] Czyczuła W., Bogacz R. i wsp. Nawierzchnia kolejowa o podwyższonym standardzie i zmniejszonym oddziaływaniu na środowisko. Raport Politechniki Krakowskiej, 2013

[4] Czyczuła W., Koziol P., Kudła D., Lisowski S. Analytical evaluation of track response in vertical direction due to moving load. Journal of Vibration and Control, 2017, 23, 18, pp. 2989-3006

[5] Czyczuła W. - Tor bezstykowy. Książka akademicka, Wydawnictwo Politechniki Krakowskiej, Kraków 2002

[6] Grassie S.L. The dynamic response of railway track to high frequency lateral excitation. Journal of Mechanical Engineering Sciences, 1982, 24,2, pp. 91-96

[7] Hunt G.A. Dynamic analysis of railway vehicle/track interaction forces. Doctoral thesis, Loughborough University, 1986

[8] Kerr A.D. The continuously supported rail subjected to axial force and moving load. Int. Journal of Mechanical Science, 1972, 14, pp. 71-78

[9] Koziol P. Wavelet approach for vibration analysis of beam-soil structures. Vibration of dynamically loaded systems. VDM Verlag, Dr Muller, Saarbrucken, 2010 
[10] Kostovasilis D., Thompson D. The effect of vertical-lateral coupling vibration of rails including initial curvature. Proc. of $22^{\text {th }}$ Int. Congress of Sound and Vibrations, 2015, pp. $1-8$

[11] Markine V., Esveld C. Analysis of longitudinal and lateral behavior of CWR track using a computer system Longin. Delft University of Technology report, 1998

[12] Piechowiak T. Analiza symulacyjna wpływu wybranych parametrów hamulca pneumatycznego na skuteczność jego działania. Pojazdy Szynowe, 2008, nr 1, s. 14-25

[13] Van M.A. Stability of CWR track. PhD Thesis, Delft University of Technology, 1997

[14] Wei X., Wang P. Calculation and study of longitudinal forces of CWR track on deck arch bridge. Third International Conference of Transportation Engineering, Changdu, China, 2011 